\title{
The Mediating Role of Psychological Capital in the Organizational Climate and Work Engagement Relationship
}

\section{Wahid Hasyim ${ }^{\mathrm{a}}$ and Wustari L. Mangundjaya ${ }^{\mathrm{b}}$}

${ }^{a}$ Faculty of Psychology, Universitas Indonesia, Depok, Indonesia; ${ }^{b}$ Department of Industrial and Organizational Psychology, Faculty of Psychology, Universitas Indonesia, Depok, Indonesia

*Corresponding author:

Wustari L. Mangundjaya

Department of Industrial and Organizational Psychology

Faculty of Psychology, Universitas Indonesia

Depok, Jawa Barat, Indonesia

Email address: wustari@ui.ac.id 


\title{
The Mediating Role of Psychological Capital in the Organizational Climate and Work Engagement Relationship
}

\begin{abstract}
One of the goals of higher education institutions is to develop competent human resources. Supporting this aim requires contributions and involvement by lecturers and employees (academic staff) within the scope of the institution. This study examined the role of psychological capital in the relationship between organizational climate and work engagement at university $\mathrm{X}$. Using a cross-sectional approach and used convenience sampling techniques, data was collected from 360 lecturers and employees (administration staff) using an organizational climate scale (CLIOR), a work engagement scale (UWES 9) and a psychological capital scale (Psycap-12). This study was conducted at university $\mathrm{X}$ with as participants. The results showed that psychological capital mediated the relationship between organizational climate and work engagement. The findings enhance understandings of organizational climate, which serves as an essential resource for employees by stimulating psychological capital such that they are engaged in their work and give their best performance thus, contributing toward the achievement of organizational goals.
\end{abstract}

Keywords: work engagement, psychological capital, organizational climate

\section{Introduction}

Every organization has objectives and goals. As a type of organization, universities have several goals, among the most important of which is to develop human resources that can be useful to society (Ristekdikti, 2017). Moreover, universities are required to be flexible, adaptive, and innovative (Khan \& Yusoff, 2016). To support these goals, requires contributions and involvement by lecturers and employees (academic staff), as their performance has a strong impact on the organization's level of achievement (Bakker \& Demerouti, 2008).

Previous research has demonstrated that employee work engagement can enhance their participation and stimulate their best performance, thus supporting organizational goals (Lee, Wang \& Liu, 2017). Work engagement is a condition whereby an individual has a positive and fulfilling attitude toward their duties, and is characterized by vigor, dedication and absorption. In this context, vigor is defined as a high level of energy while working, whereas dedication is denotes strong involvement in one's work and absorption refers to being concentrated and happy while working (Schaufeli, 2017).

Because of its important effects on individuals and organizations, many studies have explored factors related to work engagement. Job demand resources theory identifies two main factors affecting work engagement, namely job demands and job resources (Bakker \& Demerouti, 2008). Job demands consume job resources, including physical (e.g., career opportunities, work, role clarity, performance feedback, work environment and autonomy) and psychological resources (e.g., self-efficacy, self-esteem and optimism) (Sheng, Wang, Hong, Zhu \& Zhang, 2017). 
In fact, work pressure has been continually intensifying among lecturers and employees (academic staff), who are expected to engage in multiple tasks requiring more energy and skills (Ludviga \& Kalvina, 2016). Increasing work pressure on employees burdens them with an overload of demands while often being somewhat under-equipped with response strategies (Rothmann \& Barkhuizen, 2008); thus causing them to feel stressed and undermining work engagement (Mxenge, Dywilli \& Bazana, 2014).

Previous studies have demonstrated that lack of work engagement, particularly among lecturers and academic staff, often leads employees to leave universities (Owence, Pinagase \& Matshidiso, 2014). One university survey showed that the loss of six of 13 members in one academic year was due to their lack of work engagement (Mxenge et al., 2014). Therefore, it is critical to improve work engagement in order to achieve higher rates of retention and encourage employees to give their best performance (Kim, Kolb \& Kim, 2013).

The present study explores the impacts of organizational- and individual level job resources, such as work environment and psychological resources, respectively, on minimizing the negative effects of lost energy caused by job demands. Problems that arising from an unsatisfactory and demanding work environment often do not support the strengthening of job resources among employees (Luthans \& Youssef-Morgan, 2017). The work environment that is perceived by employees who occupy the same space is called "organizational climate." Employees' perceptions are based on autonomy, cooperation, rewards, work-life balance, innovation, participation, incentives, the organization of work, relationships, sense of identification, and physical conditions of the job, among others (Suarez, Muñiz, CampilloÁlvarez, Fonseca-Pedrero \& García-Cueto, 2013). Organizational climate can be a job resource if employees perceive it positively, which is more likely to happen if they feel welcomed and accepted at their workplace. Strong job resources inspire employees to engage in their work and support organizational goals (Schaufeli, 2017). Therefore, the positive perception of organizational climate can help employees give their best job performance.

Psychological capital is important because it is a state of being, which indicates that an individual can develop this psychological resource to reach both personal and organizational goals (Luthans \& Youssef-Morgan, 2017). Psychological capital is a positive and developmental condition characterized by hope, self-efficacy, resilience and optimism. Hope is a positive motivation that drives people to success, and self-efficacy denotes an individual's confidence about their ability to execute a specific task. Resilience is a capacity to rebound from failure, whereas optimism is a positive attribution of current and future conditions (Luthans \& Youssef-Morgan, 2017). Previous research by Sheng et al. (2017) identified psychological capital as a psychological resource that has a significant impact on work engagement, and other studies have supported this conclusion with findings that high levels of psychological capital among employees engenders a more positive job performance. On the other hand, low levels of psychological capital will contribute to a negative job performance (Avey, Reichard, Luthans $\&$ Mhatre, 2011). This means that a high level of psychological capital can help employees show their best performance. 
In the current study, psychological capital is tested as a mediating variable between organizational climate and work engagement. Previous research showed that psychological capital plays a role in mediating the effects of a supportive organizational climate and employees' outcomes (Luthans, Norman, Avolio \& Avey, 2008). Psychological capital influences how employees interpret and respond to their workplace climate, such that a positive perception will stimulate their psychological resources and contribute to them giving their best performance (Schaufeli, 2017).

Based on the above background, we see job resources as the most important element that can lead to the best performance by employees. Accordingly, we derived the four following propositions:

- There is a positive correlation between organizational climate and work engagement.

- There is a positive correlation between organizational climate and psychological capital.

- There is a positive correlation between psychological capital and work engagement.

- Psychological capital plays a role in mediating organizational climate and work engagement relationship.

\section{Method}

This study used a cross-sectional approach, whereby data was collected through convenience sampling techniques from various groups working at university X. Participants in this study were 360 people working at university $\mathrm{X}$, of whom $58.3 \%$ were lecturers and the remaining were administrative staff. The average age of the participants was 38.03 (SD =9.89). We controlled the demographic variables to eliminate significant differences based on gender, age, status (lecturers or employees), and tenure with the variables we tested.

Data were collected using the survey method with distributing scales consisting of the Utrecht Work Engagement Scale (UWES-9 (Schaufeli \& Bakker, 2004)), the CLIOR Scale measuring organizational climate (Suárez, Muñiz-Fernández, Campillo-Álvarez, Fonseca-Pedrero \& García-Cueto, 2013), and the Psycap-12 scale assessing psychological capital (Luthans, Avolio, Avey \& Norman, 2007). A short explanation of each scale is provided below:

- The UWES-9 scale was adapted and translated into Bahasa Indonesia from the scale developed by Schaufeli and Bakker (2004). The scale consists of three dimensions, namely vigor, dedication and absorption, each of which includes nine items with a response format ranging from 1 (never) to 6 (everyday). The model of the scale meets the criteria for fit indices, $\mathrm{CFI}=0.91, \mathrm{RMSEA}=0.13$, dan $\mathrm{SRMR}=0.05$, thus demonstrating its validity for measuring the construct. The average coefficient $\alpha$ for this measure was .81 .

- The Psycap-12 scale was adapted and translated to Bahasa Indonesia from the scale developed by Luthans, Norman, Avolio, and Avey (2007). This scale consists of four dimensions, namely, efficacy, hope, resilience, and optimism, each of which incorporates 12 items with a response format ranging from 1 (strongly disagree) to 6 (strongly agree). The model of the scale meets the criteria for fit indices, $\mathrm{CFI}=.95, \mathrm{RMSEA}=.07$ dan 
SRMR $=.04$, thus demonstrating the scale's validity for measuring the construct. The average coefficient $\alpha$ for this measure was 0.80 .

- The CLIOR organizational climate scale was adapted and translated to Bahasa Indonesia from the scale developed by Suárez et al. (2013). The CLIOR is a unidimensional scale consisting of 13 items, for which the response format ranges from 1 (strongly disagree) to 6 (strongly agree). The model of the scale meets the criteria for fit indices, $\mathrm{CFI}=.92$, RMSEA $=.061$, dan SRMR $=.05$, thus demonstrating its validity for measuring the construct. The coefficient $\alpha$ for this measure was.89.

- The data were analysed by structural equation modelling using lavaan package version 0.523 in R Studio version 1.1.447. Maximum likelihood estimation with robust standard error and Satora-Bentler scaled chi-squared test were used to correct non-normal data distribution. The model fits were determined with fit indices as follows: the comparative fit index $(\mathrm{CFI})>0.90$, standardized root mean square residual $(\mathrm{SRMR})<0.08$, and root mean square error of approximation (RMSEA) < 0.06 (Balkar, 2015). Model fit can be identified if the model meets two of the three criteria (Jaya, Ascone \& Lincoln, 2017).

\section{Results}

\section{Descriptive Statistic Analysis and Fit Index Structural Model}

Table I presents the descriptive statistics, standard deviations, and inter-correlations between study variables. The results demonstrate that work engagement has a positive correlation with organizational climate, $\mathrm{r}=0.54, \mathrm{p}<0.01$, and psychological capital, $\mathrm{r}=0.60, \mathrm{p}<0.01$. We also found that organizational climate has a positive correlation with psychological capital, $r=0.59$, $\mathrm{p}<0.01$.

Table I. Mean, Standard Deviations, and Inter-Correlation Between Study Variable

\begin{tabular}{llllll}
\hline Variable & Mean & SD & $\mathbf{1}$ & $\mathbf{2}$ & $\mathbf{3}$ \\
\hline $\begin{array}{l}\text { Work } \\
\text { Engagement }\end{array}$ & 5.00 & 0.80 & - & & \\
$\begin{array}{l}\text { Organizational } \\
\text { Climate }\end{array}$ & 4.70 & 0.60 & $0.54^{* *}$ & - & \\
$\begin{array}{l}\text { Psychological } \\
\text { Capital }\end{array}$ & 5.00 & 0.70 & $0.60^{* *}$ & $0.59^{* *}$ & - \\
\hline & & & & & \\
\hline
\end{tabular}

Table II provides information about fit indices for the models that we tested. The results show that the direct model and mediation model could be identified and met the criteria for fit indexes (Jaya et al., 2017). 
Table II. Fit Statistic From Structural Model

\begin{tabular}{|c|c|c|c|c|c|c|}
\hline \multirow[t]{2}{*}{ Model } & \multicolumn{3}{|c|}{ Satora-Bentler $X^{2}$} & \multirow[t]{2}{*}{ RMSEA } & \multirow[t]{2}{*}{$\overline{S R M R}$} & \multirow[t]{2}{*}{ CFI } \\
\hline & $x^{2}$ & $d f$ & $P$ & & & \\
\hline $\begin{array}{l}\text { Direct } \\
\text { model }^{\text {a }}\end{array}$ & 918.30 & 518 & $<0.01$ & 0.05 & 0.07 & 0.90 \\
\hline $\begin{array}{l}\text { Mediation } \\
\text { model }^{\text {b }}\end{array}$ & 874.45 & 518 & $<0.01$ & 0.05 & 0.06 & 0.91 \\
\hline
\end{tabular}

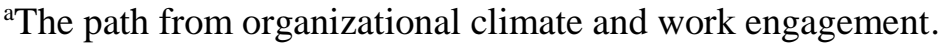

${ }^{b}$ The path from organizational climate and work engagement with psychological capital as mediator.

\section{Test Hypotheses}

The analysis showed that all of the hypotheses are accepted. The results confirmed that hypothesis 1 is supported, and that organizational climate is positively correlated with work engagement $(\beta=0.63, p<.0 .01)$. As shown in Fig. 1 , hypothesis 2 was also confirmed, and organizational climate has a positive correlation with psychological capital $(\beta=0.66, p<.0 .01)$.

Hypothesis 3, which proposed that psychological capital was positively correlated with work engagement, is shown to be supported in Fig. $1(\beta=0.57, \mathrm{p}<.0 .01)$. Hypothesis 4 proposed that psychological capital plays a role in mediating the relationship between organizational climate and work engagement. As Fig. 1 illustrates, the total effect of the mediation variable supports hypothesis 4 , thus providing for its acceptance $(\beta=0.63, \mathrm{p}<.0 .01)$. We also found that there is a reduced correlation between the dependent variables after adding the mediating variable (from $\beta=0.63, \mathrm{p}<.0 .01$ to $\beta=0.57$, ns.), which demonstrates that psychological capital plays a role as a mediator and provides support for full mediation (Baron \& Kenny, 1986).

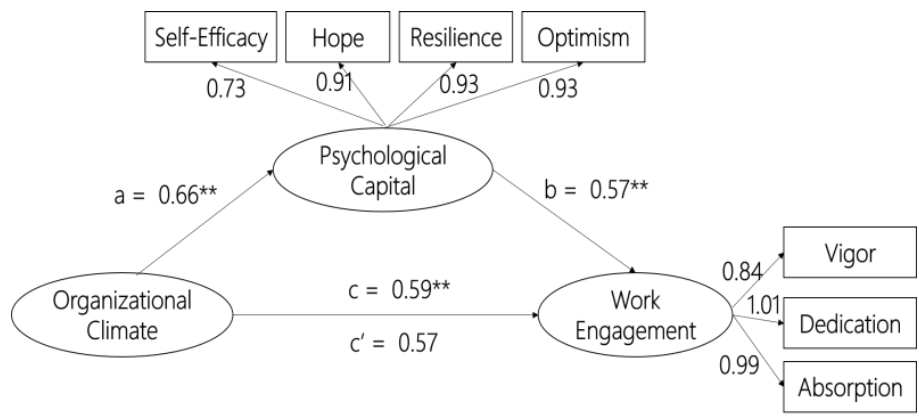

Fig. 1. Results of Mediation Model.

\section{Discussion}

This study aimed to identify the role of psychological capital in mediating the relationship between organizational climate and work engagement at university $\mathrm{X}$. This study provided an antecedent for work engagement, especially at the individual and organizational levels, and it examined the mechanisms influencing this variable. All of the hypotheses proposed in this study are supported. First, organizational climate is positively correlated with work engagement. Second, organizational climate has a positive correlation with psychological capital. Third, psychological capital is positively correlated with work engagement. Fourth, psychological 
capital plays a role in mediating the relationship between organizational climate and work engagement.

The results showed that organizational climate has a positive correlation with work engagement. These findings support previous research demonstrating that a supportive organizational climate enhances employee satisfaction and thereby promotes their efforts toward best performance (Luthans et al., 2008). As a job resource, a positively perceived organizational climate stimulates employees to give their best performance [15]. Job resources (in this case organizational climate) can support employees, and reduce the chances of them experiencing exhaustion or burnout due to job demands or high levels of other work stressors (Bakker \& Demerouti, 2008). In a university, organizational climate is the best component to provide energy to lecturers and academic staff to give their best performance (Sokol, Gozdeg, Figurska \& Blaskova, 2014). A positive organizational climate functions as a job resource that helps employees engage with their work and thereby support organizational goals.

The results also showed that organizational climate is positively correlated with psychological capital. Based on the results, we found that as a job resource obtained from work environment, a positively perceived organizational climate provides energy to psychological resources (Luthans et al., 2008). We determined that resilience and optimism are important factors that mediate between organizational climate and work engagement, which supports the theory that a supportive organizational climate promotes increases in these mediating factors among employees (Luthans et al., 2008). This demonstrates that the organizational climate of university $\mathrm{X}$ is among the factors supporting the employees to improve their psychological capital. Thus, the result of this study supports the theory that organizational climate is a good antecedent to predict psychological capital (Luthans \& Youssef-Morgan, 2017).

Further, by demonstrating that psychological capital is positively correlated with work engagement, these results indicate that a high level of psychological capital among employees promotes good outcomes for themselves as well as their organization (Luthans, et. al., 2007). Work engagement is related to employees' sense of well-being, a perfect state that allows them to experience positive emotions while at their workplace (Sheng et al., 2017). As a factor promoting employees' well-being, work engagement will be achieved if employees have adequate psychological resources, which will reduce the negative pressures of high job demands (Schaufeli, 2017). This result is a solution for the overload of demand among university staff members, as they will engage with their work more easily and productively if they have high levels of psychological capital (Erbasi \& Ozbek, 2016). Thus, a high level of psychological capital enhances employees' work engagement.

In addition, the results showed that psychological capital plays a role in mediating the relationship between organizational climate and work engagement. In this study, we found that psychological capital serves as a full mediator in this relationship, thereby functioning as a mechanism to increase the employees' work engagement. If employees perceive it positively, organizational climate should affect psychological capital by giving them energy and stimulating their work engagement. The results confirmed this theory, thus demonstrating that 
psychological capital is a state-like resource, which means that it can be improved among employees, as it can be affected by many factors, including the organizational climate (Luthans \& Youssef-Morgan, 2017). A positive perception of organizational climate can provide a positive energy to enhance employees' psychological capital, which in turn will increase their level of engagement with their work (Luthans et al., 2008). Other research has also found that psychological capital plays a role if the organizational climate is supportive, which results in employees giving their best performance (Luthans et al., 2008). The results of this study confirmed that psychological capital in lecturers and academic staff plays a role in mediating between organizational climate and work engagement.

\section{Conclusions and Implications}

The results of the study demonstrate psychological capital to be a significant variable in developing work engagement. However, the environment as perceived by employees is also essential as a resource because it can provide energy to their psychological resources. A high level of psychological resources (psychological capital) is the most important factor in improving employee engagement and ultimately improves employee performance. However, if the employee does not gain sufficient energy from their work environment, this can cause the employee to experience burnout or exhaustion. Exhaustion and burnout result when employees perceive their organizational climate negatively and their psychological resources are low.

The present study has several limitations that should be considered. First, the data were collected using convenience sampling, and therefore the results cannot be generalized. Second, this study only included mediating variables on organizational climate and work engagement. Further research should explore several other variables or test the dimension of psychological capital as a mediation/moderation variable.

This study can be useful for society, primarily by helping organizations or practitioners to develop interventions and create a supportive work environment that supports employees in a manner that enables them to develop their psychological capital, thus engaging them with their work. Organizations can also provide training, coaching or counselling to establish or improve the psychological capital of their employees, which will enable them to better engage with their work and give their best performance.

\section{References}

Avey, J. B., Reichard, R. J., Luthans, F., \& Mhatre, K. H. (2011). Meta-analysis of the impact of positive psychological capital on employee attitudes, behaviors, and performance. Human Resource Development Quarterly, 22(2), 127-152. doi: 10.1002/hrdq.20070.

Bakker, A. B., \& Demerouti, E. (2008). Towards a model of work engagement. Career Development International, 13(3), 209-223. doi: 10.1108/13620430810870476.

Bakker, A. B., Schaufeli, W. B., Leiter, M. P., \& Taris, T. W. (2008). Work engagement: an emerging concept in occupational health psychology. Work \& Stress, 22(3), 187-200. doi: 10.1080/02678370802393649.

Balkar, B. (2015). The relationships between organizational climate, innovative behavior and job performance of teachers. International Online Journal of Educational Sciences, 7(2), 81-92. 
Baron, R. M., \& Kenny, D. A. (1986). The moderator-mediator variable distinction in social psychological research: conceptual, strategic, and statistical considerations. Journal of Personality and Social Psychology, 51(6), 1173-1182. doi: 10.1037/0022-3514.51.6.1173. PubMed: 3806354.

Erbasi, A., \& Ozbek, M. C. (2017). The effect of psychological capital on work engagement. Australian Academy of Business and Economics Review, 2(4), 276-284.

Jaya, E. S., Ascone, L., \& Lincoln, T. M. (2017). Social adversity and psychosis: the mediating role of cognitive vulnerability. Schizophrenia Bulletin, 43(3), 557-565. doi: 10.1093/schbul/sbw104. PubMed: 27451429.

Khan, A., \& Yusoff, R. B. (2016). A study on dynamic links between resources, work engagement and job performance in academia of Pakistan. International Review of Manaagement and Marketing, 6(3), 544550 .

Kim, W., Kolb, J. A., \& Kim, T. (2013). The relationship between work engagement and performance: A review of empirical literature and a proposed research agenda. Human Resource Development Review, 12(3), 248-276. doi: 10.1177/1534484312461635.

Lee, C. H., Wang, M. L., \& Liu, M. S. (2017). When and How Does Psychological Voice Climate Influence Individual Change Readiness? The Mediating Role of Normative Commitment and the Moderating Role of Work Engagement. Frontiers in psychology, 8, 1737.

Ludviga, I., \& Kalvina, A. (2016). Exploring the Relationships between Job Satisfaction, Work Engagement and Loyalty of Academic Staff. International Journal of Economics and Management Engineering, 10(1), 99-101.

Luthans, F., \& Youssef-Morgan, C. M. (2017). Psychological capital: An evidence-based positive approach. Annual Review of Organizational Psychology and Organizational Behavior, 4(1), 339-366.

Luthans, F., Avolio, B. J., Avey, J. B., \& Norman, S. M. (2007). Positive psychological capital: Measurement and relationship with performance and satisfaction. Personnel psychology, 60(3), 541-572.

Luthans, F., Norman, S. M., Avolio, B. J., \& Avey, J. B. (2008). The mediating role of psychological capital in the supportive organizational climate-employee performance relationship. Journal of Organizational Behavior: The International Journal of Industrial, Occupational and Organizational Psychology and Behavior, 29(2), 219-238.

Mxenge, S. V., Dywill, M., \& Basaza, S. (2014). Job engagement and employees' intention to quit among administrative personnel at the University of Fort Hare in South Africa. International Journal of Research in Social Sciences, 4(5), 129-144.

Owence, C., Pinagase, T. G., \& Mercy, M. M. (2014). Causes and effects of staff turnover in the Academic Development Centre: A case of a historically black university in South Africa. Mediterranean Journal of Social Sciences, 5(11), 69.

Ristekdikti (2017). Pemeringkatan untuk meningkatkan mutu perguruan tinggi. Retrieved from http://kelembagaan.ristekdikti.go.id/index.php/2017/08/07/pemeringkatan-untuk-meningkatkan-mutuperguruan-tinggi.

Rothmann, S., \& Barkhuizen, N. (2008). Burnout of academic staff in South African higher education institutions. South African Journal of Higher Education, 22(2), 439-456.

Schaufeli, W. B., \& Bakker, A. B. (2003). Utrecht work engagement scale: Preliminary manual. Occupational Health Psychology Unit, Utrecht University, Utrecht, 26.

Schaufeli, W. B. (2017). Applying the job demand-resources model: a 'how to' guide to measuring and tackling work engagement and burnout. Organizational Dynamic, 46, 120-132.

Sheng, X., Wang, Y., Hong, W., Zhu, Z., \& Zhang, X. (2017). The curvilinear relationship Between daily time pressure and work engagement: The role of psychological capital and sleep. International Journal of Stress Management, 26(1), 25-35. doi: 10.1037/str0000085.

Sokol, A., Gozdek, A., Figurska, I., \& Blaskova, M. (2015). Organizational climate of higher education institutions and its implications for the development of creativity. Procedia-Social and Behavioral Sciences, 182, 279-288.

Peña Suárez, E., Muñiz Fernández, J., Campillo Álvarez, Á., Fonseca Pedrero, E., \& García Cueto, E. (2013). Assessing organizational climate: Psychometric properties of the CLIOR Scale. Psicothema, 25(1). 
Yalabik, Z. Y., Popaitoon, P., Chowne, J. A., \& Rayton, B. A. (2013). Work engagement as a mediator between employee attitudes and outcomes. The International Journal of Human Resource Management, 24(14), 2799-2823. 